Cite as: Barral, C., Eiroa-Orosa, F. J., Navarro-Marfisis, M. C., Roncero, C., \& Casas, M. (2015). Assessing knowledge and attitudes towards addictions in medical residents of a general hospital. Drugs:

Education, Prevention and Policy, 22(6), 457-462. http://doi.org/10.3109/09687637.2014.987218

\title{
Assessing knowledge and attitudes towards addictions in medical residents of a general hospital
}

Barral, C. ${ }^{1,2,3}$, Eiroa-Orosa, F.J. ${ }^{4}$, Navarro-Marfisis, M.C. ${ }^{1}$, Roncero, C. ${ }^{1,2,3}$, Casas, M. ${ }^{1,2}$

1. Department of Psychiatry, Hospital Universitari Vall d'Hebron, CIBERSAM, Universitat Autònoma de Barcelona. Spain.

2. Outpatient Drug Clinic Vall Hebron, Department of Psychiatry, Hospital Universitari Vall d'Hebron - Agència de Salut Pública de Barcelona

3. Department of Psychiatry and Legal Medicine, Universitat Autònoma de Barcelona. Spain.

4. School of Psychology, University of East London.

Address of correspondence:

Carmen Barral Picado

Department of Psychiatry

Hospital Universitari Vall d'Hebron

Passeig Vall d'Hebron, 119-129

08035 Barcelona, Spain

cbarral@vhebron.net 
Cite as: Barral, C., Eiroa-Orosa, F. J., Navarro-Marfisis, M. C., Roncero, C., \& Casas, M. (2015). Assessing knowledge and attitudes towards addictions in medical residents of a general hospital. Drugs:

Education, Prevention and Policy, 22(6), 457-462. http://doi.org/10.3109/09687637.2014.987218

\title{
Assessing knowledge and attitudes towards addictions in medical residents of a general hospital
}

\begin{abstract}
Aims

Addiction treatment training has been recognized to be an essential part of the curriculum in psychiatry and general medicine. Our objective in this study was to measure the knowledge and attitudes towards addictions among medical residents of a general hospital in Catalonia, Spain.
\end{abstract}

Method

Within a sample of medical residents, we administered a questionnaire based on previous literature including attitudes towards patients with drug use problems, evaluation of knowledge and beliefs about harm reduction policies. Additionally, basic professional data, and personal as well as family consumption history were recorded.

Findings

Four dimensions were found within the beliefs of medical residents about drug treatment and training: judgement of medical treatment of addictions and harm reduction, attitudes toward patients, importance given to training and assessment of training received. When correlating these dimensions with personal characteristics, we found those residents with personal or family history of drug use to have higher positive attitudes towards patients with addictions, and also better predisposition towards harm reduction policies. Residents working with these patients tended to give more importance to training and knowledge, and to have a better perception of the training already received, compared with residents without this contact.

Conclusions

Although residents working often with addicted patients appear to have positive attitudes towards addiction treatment, according to our results, it seems very important to improve 
Cite as: Barral, C., Eiroa-Orosa, F. J., Navarro-Marfisis, M. C., Roncero, C., \& Casas, M. (2015). Assessing knowledge and attitudes towards addictions in medical residents of a general hospital. Drugs:

Education, Prevention and Policy, 22(6), 457-462. http://doi.org/10.3109/09687637.2014.987218

training policies, awareness and attitudes towards addiction among the whole medical community.

Keywords: Training, substance use disorders, attitudes, treatment, medical residents. 
Cite as: Barral, C., Eiroa-Orosa, F. J., Navarro-Marfisis, M. C., Roncero, C., \& Casas, M. (2015). Assessing knowledge and attitudes towards addictions in medical residents of a general hospital. Drugs:

Education, Prevention and Policy, 22(6), 457-462. http://doi.org/10.3109/09687637.2014.987218

\section{Introduction}

Health problems directly related to Substance Use Disorders (SUDs) and its comorbidities are a source of frequent consultation in daily clinical practice. According to a recent European Monitoring Centre for Drugs and Drug Addiction's (2010) report, 1 million Europeans received treatment for problems related to the use of illicit drugs in 2009. However, despite the fact that SUDs represent a fairly common problem, its diagnosis and treatment remains largely unnoticed or misdiagnosed as reflected in several studies (Miller \& Sheppard, 1999; Saitz et al., 2002; Saitz, Mulvey, Plough, \& Samet, 1997). According to these studies, approximately $20 \%$ of emergency patients assessed on an outpatient basis are estimated to meet criteria for substance use disorder (SUD), being only $5 \%$ of them correctly diagnosed.

The failure to identify addiction problems by the medical community may lead to complications of medical illnesses and poor response to conventional therapies, therefore leading to poor outcomes (Gili Miner, Giner, Lacalle, Franco, \& Velasco, 1990). Several factors have been proposed as an explanation of low SUDs diagnosis. Among these factors, stand out inadequate or lack of training in the field of addictions, certain characteristics of work settings (such as high stress in emergencies), the burden of care, and prejudices of the professionals regarding patients diagnosed with SUDs (Ballon \& Skinner, 2008; Friedmann, McCullough, \& Saitz, 2001; Saitz et al., 2002). These prejudices include biases such as negative and pessimistic views of patients' prognosis, and the false perception of poor response to therapeutic interventions (Friedmann et al., 2001; Lawrence, Rasinski, Yoon, \& Curlin, 2013). In addition, the subjective perception of professionals about substance use may influence their ability to correctly diagnose addiction problems. 
Cite as: Barral, C., Eiroa-Orosa, F. J., Navarro-Marfisis, M. C., Roncero, C., \& Casas, M. (2015). Assessing knowledge and attitudes towards addictions in medical residents of a general hospital. Drugs:

Education, Prevention and Policy, 22(6), 457-462. http://doi.org/10.3109/09687637.2014.987218

Despite sanctions in some countries, physicians' own consumption is very common. Several studies have reported high rates of alcohol consumption among medical residents compared to the general population (McBeth \& Ankel, 2006). By contrast, another study found mixed results when comparing medical students with their age mates in the general population (Flaherty \& Richman, 1993). The prevalence of SUDs among doctors and medical students is near to $14 \%$, being specialities such as anaesthesiology, psychiatry and emergency medicine the most related with substance use problems (Beletsky et al., 2007; Choi, Tolova, Socha, \& Samenow, 2013; Cottler et al., 2013; Rose, Campbell, \& Skipper, 2014). As denial is a common feature among people with substance use problems, it might be expected that the exposure of medical residents to substance use (both regarding themselves and their circle of friends or family), would minimize their ability to self-detect them and seek help (Miller, Sheppard, Colenda, \& Magen, 2001).

Research has linked attitudes and level of addiction treatment training (specifically harm-reduction approaches), to therapeutic outcomes (Beletsky et al., 2007; Deren, Kang, Mino, \& Seewald, 2011; Gerlach \& Caplehorn, 1999; Goddard, 2003). This points to the need of making an integrated change in medical internship programmes (Ding et al., 2005). Such changes might be carried adding drug treatment and harm reduction training through novel experiential methods (Barron, Frank, \& Gitlow, 2012; International Centre for Drud Policy, 2007; Notley et al., 2014), as well as paying special attention to professional's attitudes towards patients with SUDs (Chappel, 1993; Deren et al., 2011; Renner, 2004). On the other hand, correctly addressing the potential trainees' past or current consumption, might also help to improve their attitudes, knowledge and medical education (Carroll et al., 2014). In this regard, several physician's health programs have been developed to treat 
Cite as: Barral, C., Eiroa-Orosa, F. J., Navarro-Marfisis, M. C., Roncero, C., \& Casas, M. (2015). Assessing knowledge and attitudes towards addictions in medical residents of a general hospital. Drugs:

Education, Prevention and Policy, 22(6), 457-462. http://doi.org/10.3109/09687637.2014.987218

professionals with SUDs achieving high success in recovery and return to clinical practise (Rose et al., 2014).

\section{Measuring knowledge and attitudes towards addictions}

Previous literature has intended to address physician's and medical students knowledge and attitudes towards addictions in several settings (such as primary care, general psychiatry or specialised addiction services), underscoring the importance of training and supervisor's support (Gilchrist et al., 2011; Howard \& Holmshaw, 2010; Kelleher \& Cotter, 2009), and the need to improve different aspects of medical education (Carroll et al., 2014). In this regard, the need to integrate addiction training into the general medical curriculum, with the objective of overcoming the lack of knowledge in this area, has been already highlighted (Strobel et al., 2012). Van Boekel, Brouwers, Van Weeghel, \& Garretsen (2013) recently published an extensive review on the stigma towards patients with addiction problems among health professionals, in which they underscore the negative consequences of these attitudes.

Previous studies have designed several questionnaires to measure medical professionals' knowledge and attitudes towards addicted patients (Barone, Huggett, \& Lofgreen, 2011; Barron, Frank, \& Gitlow, 2012; Lindberg, Vergara, Wild-Wesley, \& Gruman, 2006). Although these studies report valuable information, to our knowledge few studies have been developed with medical residents. Karam-Hage, Nerenberg, \& Brower (2001) used a questionnaire to assess beliefs, attitudes and expectations about addiction treatment before and after an educational conference carried with residents. Saitz et al. (2002) used questionnaires to survey 157 faculty physicians and residents, finding relation of posittive attitudes with perceived resposibility and satisfaction, but no relation with 
Cite as: Barral, C., Eiroa-Orosa, F. J., Navarro-Marfisis, M. C., Roncero, C., \& Casas, M. (2015). Assessing knowledge and attitudes towards addictions in medical residents of a general hospital. Drugs:

Education, Prevention and Policy, 22(6), 457-462. http://doi.org/10.3109/09687637.2014.987218

interpersonal experience with SUDs. Finally, Lindberg et al. (2006) pointed to a deteriorating perception of overutilization of health care resources and loss of satisfaction, when caring addicted patients over years in training.

Based on these previous experiences, in this study we intend to describe knowledge and attitudes towards patients with SUDs, among a sample of resident physicians in a large university hospital, using an adapted version of the questionnaire proposed by Karam-Hage et al. (2001). In addition, we also intended to assess resident's personal and interpersonal experiences with drug use and its relation with knowledge and attitudes in this field. We believe that the importance of the study lies in the potential influence of these factors on the correct diagnosis and treatment of patients with SUDs.

\section{Methods}

\section{Design.}

A cross-sectional design was used. A self-reported questionnaire was administered anonymously online.

\section{Subjects.}

Residents (N=533) of all specialties in the largest university hospital of Catalonia and second largest in Spain, were invited to participate in the study. Electronic mailing was used to invite each participant to an on-line survey. Three emails were sent within three months. 
Cite as: Barral, C., Eiroa-Orosa, F. J., Navarro-Marfisis, M. C., Roncero, C., \& Casas, M. (2015). Assessing knowledge and attitudes towards addictions in medical residents of a general hospital. Drugs:

Education, Prevention and Policy, 22(6), 457-462. http://doi.org/10.3109/09687637.2014.987218

\section{Measures.}

The online survey was composed of two parts. First, a part including basic demographic (residence year, gender, age, origin, type of specialty), experience with addicted patients and any personal or family problematic experience with drugs. In addition, a second part included a questionnaire about beliefs and attitudes towards addictions, partially based on the work of Karam-Hage, Nerenberg, \& Brower (2001) and adapted ad-hoc to our context. As in Spain, medical residents already have chosen and practice a specific speciality; we removed questions about future professional fellowships. Furthermore, as harm reduction, evidence based interventions and health resources availability are current and important debates in the field of addiction treatment, we added 3, 4 and 2 questions about these issues respectively. The questionnaire was previously tested with a small sample $(n=4)$ of medical residents, to check for coherence and applicability.

The design of the questionnaire made compulsory to reply to all questions and they scored according to a Likert 1-5 scale, with 5 expressing total agreement. No personal data was recorded and confidentiality was granted by the Hospital Training Board. The study was approved by the Clinical Research Ethics Committee of the Hospital and no remuneration was provided to the participants.

\section{Data Analysis.}

In the first place, an analysis of acquiescence was developed in order to clean the sample from possible outliers (consisting on looking at subjects with extremely low, high and medium punctuations). In addition, descriptive analyses of the sample were performed using univariate statistics. Furthermore, exploratory factor analyses were combined in 
Cite as: Barral, C., Eiroa-Orosa, F. J., Navarro-Marfisis, M. C., Roncero, C., \& Casas, M. (2015). Assessing knowledge and attitudes towards addictions in medical residents of a general hospital. Drugs:

Education, Prevention and Policy, 22(6), 457-462. http://doi.org/10.3109/09687637.2014.987218

order to test the construct validity of the questionnaire. Reliability was checked using Cronbach's alpha. Finally, bivariate tests (Pearson's r, t-test, and Mann-Whitney U) were carried in order to correlate the attitudes towards addictions with sociodemographic and training characteristics among study participants.

\section{Results}

\section{Sociodemographic and addiction characteristics}

One hundred seventy one residents (32\%) replied to the survey between January and April 2011. The analysis of acquiescence yielded no outliers, considering both addiction information and questionnaire scores. The sociodemographic characteristics of the sample can be observed in table 1 .

Table 1. Sociodemographic characteristics of the sample

\begin{tabular}{lll}
\hline Variable & M & SD \\
\hline Age & 27.90 & 2.34 \\
\hline Gender (female) & $\mathrm{N}$ & $\%$ \\
\hline Residence year & 107 & 62.6 \\
First & & \\
Second & 51 & 29.8 \\
Third & 41 & 24.0 \\
Fourth & 36 & 21.1 \\
Fifth* & 33 & 19.3 \\
\hline Specialty & 10 & 5.8 \\
Medical & & \\
Medical-surgical & 91 & 53.2 \\
Surgical & 39 & 22.8 \\
\hline Origin & 39 & 22.8 \\
Catalonia & & \\
Rest of Spain & 74 & 43.3 \\
Foreign countries & 31 & 18.1 \\
Contact with addicted patients in everyday practice & 66 & 38.6 \\
\hline *In Spain, the average in medical residence last four years although some specialties such as internal \\
medicine, surgeries or traumatology last five years.
\end{tabular}


Cite as: Barral, C., Eiroa-Orosa, F. J., Navarro-Marfisis, M. C., Roncero, C., \& Casas, M. (2015). Assessing knowledge and attitudes towards addictions in medical residents of a general hospital. Drugs:

Education, Prevention and Policy, 22(6), 457-462. http://doi.org/10.3109/09687637.2014.987218

\section{Validation of the Resident's Beliefs and Attitudes Questionnaire.}

First an exploratory factor analysis was carried using principal components extraction and Varimax rotation in order to maximize the independence of the dimensions of the questionnaire. Based in the scree plot we decided to keep four factors named:

1. "Agreement with medical treatment of addictions and harm reduction": $22.91 \%$ variance explained. Reliability: $\alpha=.800$.

2. "Daily attitudes toward patients" $10.88 \%$ variance explained. Reliability: $\alpha=.717$.

3. "Importance of training / knowledge" $7.56 \%$ variance explained. Reliability: $\alpha=.648$.

4. "Assessment of own training" $6.47 \%$ variance explained. Reliability: $\alpha=.328$.

Factor loadings can be seen in table 2. A total of $47.83 \%$ of variance was explained by the final extraction. The correlation matrix between subscales can be seen in table 3 .

\section{Correlations with sociodemographic and experience with patients with addictions}

A low inverse correlation was found between age with the assessment of the own training $(\mathrm{r}=-.161, \mathrm{p}<.05)$, residence year and agreement with harm reduction $(\mathrm{r}=-.156$, $\mathrm{p}<.05)$, and the importance of the training received $(\mathrm{r}=-.175, \mathrm{p}<.05)$. No gender differences were found. Residents working with patients with addictions were found to give more importance to training and knowledge $(\mathrm{t}=2.844, \mathrm{p}<.005)$ and to better assess the training already received $(\mathrm{t}=5.832, \mathrm{p}<.005$, although this relation should be analysed cautiously because of the low reliability of the subscale). Residents with family history of drug problematic use were found to have better attitudes towards patients with addictions $(\mathrm{t}=-$ $2.556, \mathrm{p}<.05)$ and a statistical tendency to give more importance to training and knowledge 
Cite as: Barral, C., Eiroa-Orosa, F. J., Navarro-Marfisis, M. C., Roncero, C., \& Casas, M. (2015). Assessing knowledge and attitudes towards addictions in medical residents of a general hospital. Drugs:

Education, Prevention and Policy, 22(6), 457-462. http://doi.org/10.3109/09687637.2014.987218

$(\mathrm{t}=-1.900, \mathrm{p}=.059)$. Residents which believed that had a problem with drugs agreed more with harm reduction policies $(\mathrm{Z}=-2.838, \mathrm{p}<.005)$.

Table 2. Factor analysis of the Beliefs and Attitudes Questionnaire

\begin{tabular}{|c|c|c|c|c|}
\hline Item & $\begin{array}{l}\text { Agreement } \\
\text { with medical } \\
\text { treatment of } \\
\text { addictions } \\
\text { and harm } \\
\text { reduction }\end{array}$ & $\begin{array}{l}\text { Daily } \\
\text { attitudes } \\
\text { toward } \\
\text { patients }\end{array}$ & $\begin{array}{l}\text { Importance } \\
\text { of training / } \\
\text { knowledge }\end{array}$ & $\begin{array}{l}\text { Assessment } \\
\text { of own } \\
\text { training }\end{array}$ \\
\hline $\begin{array}{l}\text { It is important to have a harm reduction program } \\
\text { in substance abuse services }\end{array}$ & .845 & & & \\
\hline $\begin{array}{l}\text { I believe it's necessary to have knowledge about } \\
\text { harm reduction programs }\end{array}$ & .777 & & & \\
\hline $\begin{array}{l}\text { I believe addictions must be treated in health } \\
\text { systems }\end{array}$ & .669 & & & \\
\hline $\begin{array}{l}\text { Injection rooms are necessary in a harm reduction } \\
\text { program }\end{array}$ & .666 & & & \\
\hline Addiction has a neurobiological basis & .620 & & & \\
\hline $\begin{array}{l}\text { I believe we need more resources to treat drug- } \\
\text { dependent patients }\end{array}$ & .570 & & & \\
\hline $\begin{array}{l}\text { Treatment of alcohol use disorders and other drugs } \\
\text { worth the effort }\end{array}$ & .469 & & & \\
\hline $\begin{array}{l}\text { I believe the problem of addiction in my patients is } \\
\text { an important issue }\end{array}$ & .407 & & & \\
\hline $\begin{array}{l}\text { It is common to have bad experiences in dealing } \\
\text { drug dependent patients with }\end{array}$ & & -.696 & & \\
\hline $\begin{array}{l}\text { I enjoy working with patients who have an } \\
\text { addiction problem }\end{array}$ & & .676 & & \\
\hline It is frustrating to work with drug addicted patients & & -.669 & & \\
\hline $\begin{array}{l}\text { I like to do clinical practice drug dependent } \\
\text { patients }\end{array}$ & & .635 & & \\
\hline $\begin{array}{l}\text { Most often drug addicted patients abandon } \\
\text { medical treatment }\end{array}$ & & -.512 & & \\
\hline $\begin{array}{l}\text { I try to avoid patients with addiction problems and } \\
\text { transfer their care to someone else }\end{array}$ & & -.397 & & \\
\hline $\begin{array}{l}\text { Addiction is more a character problem than a } \\
\text { disease }\end{array}$ & & -.389 & & \\
\hline $\begin{array}{l}\text { I believe I need training in addictions for my daily } \\
\text { clinical practice }\end{array}$ & & & .787 & \\
\hline I would like more training on addictions & & & .744 & \\
\hline $\begin{array}{l}\text { I often ask my patients about their toxicological } \\
\text { history }\end{array}$ & & & .556 & \\
\hline $\begin{array}{l}\text { I think it's important to have knowledge about the } \\
\text { consequences of continued use of substances for } \\
\text { clinical practice }\end{array}$ & & & .506 & \\
\hline I am prepared to deal with addicted patients & & & & .662 \\
\hline $\begin{array}{l}\text { Undergraduate training in the addiction field was } \\
\text { adequate }\end{array}$ & & & & .552 \\
\hline $\begin{array}{l}\text { Treatment of addiction is based on empirical } \\
\text { evidence }\end{array}$ & & & & .395 \\
\hline
\end{tabular}

47.83 explained variance 
Cite as: Barral, C., Eiroa-Orosa, F. J., Navarro-Marfisis, M. C., Roncero, C., \& Casas, M. (2015). Assessing knowledge and attitudes towards addictions in medical residents of a general hospital. Drugs:

Education, Prevention and Policy, 22(6), 457-462. http://doi.org/10.3109/09687637.2014.987218

Table 3. Correlations between subscales

\begin{tabular}{lllll}
\hline & $\begin{array}{l}\text { Agreement } \\
\text { with harm } \\
\text { reduction }\end{array}$ & $\begin{array}{l}\text { Daily } \\
\text { attitudes } \\
\text { toward } \\
\text { patients }\end{array}$ & $\begin{array}{l}\text { Importance of } \\
\text { training / } \\
\text { knowledge }\end{array}$ & $\begin{array}{l}\text { Assessment of } \\
\text { own training }\end{array}$ \\
\hline $\begin{array}{l}\text { Agreement with } \\
\text { harm reduction }\end{array}$ & 1 &, $308^{* * *}$ &, $463 * * *$ &,- 061 \\
$\begin{array}{l}\text { Daily attitudes } \\
\text { toward patients }\end{array}$ & 1 &, $324 * * *$ &, $159^{*}$ \\
$\begin{array}{l}\text { Importance of } \\
\text { training / }\end{array}$ & & 1 &,- 003 \\
$\begin{array}{l}\text { knowledge } \\
\text { Assessment of } \\
\text { own training }\end{array}$ & & & \\
\hline$*$ p $<.05$ & & & \\
$* * \mathrm{p}<.01$ & & & \\
$* * * \mathrm{p}<.001$ & & & \\
\hline
\end{tabular}

\section{Drug consumption among medical residents}

Table 4 shows own consumption and family history among medical residents. Although more than three quarters of the sample reported having consumed any drug, and more than a half any illegal drug, only $3.5 \%$ of the sample reported having problems with at least one substance. When sociodemographic variables were correlated with consumption variables a relation with gender was found in relation with lifetime consumption of any drug $\left(\chi^{2}=5.036, p=.025\right)$ and alcohol $\left(\chi^{2}=4.636, p=.031\right)$, cannabis (Fisher's exact test $\mathrm{p}<.0001)$ consumption in the last 30 days. More cannabis consumption was found among native-born residents $\left(\chi^{2}=4.273, \mathrm{p}=.039\right)$. No statistically significant differences were found by medical specialty (as said before, in order to preserve confidentiality only 3 categories were registered). 
Cite as: Barral, C., Eiroa-Orosa, F. J., Navarro-Marfisis, M. C., Roncero, C., \& Casas, M. (2015). Assessing knowledge and attitudes towards addictions in medical residents of a general hospital. Drugs:

Education, Prevention and Policy, 22(6), 457-462. http://doi.org/10.3109/09687637.2014.987218

Table 4. Own consumption and family history among medical residents

\begin{tabular}{|c|c|c|c|c|c|c|c|c|c|c|c|c|c|c|}
\hline & \multicolumn{2}{|l|}{ Any } & \multicolumn{2}{|c|}{ Alcohol } & \multicolumn{2}{|c|}{ Cannabis } & \multicolumn{2}{|c|}{ Cocaine } & \multicolumn{2}{|c|}{ Opiates } & \multicolumn{2}{|c|}{ Amphetamines } & \multicolumn{2}{|c|}{ Others } \\
\hline & $\mathrm{N}$ & $\%$ & $\mathrm{~N}$ & $\%$ & $\mathrm{~N}$ & $\%$ & $\mathrm{~N}$ & $\%$ & $\mathrm{~N}$ & $\%$ & $\mathrm{~N}$ & $\%$ & $\mathrm{~N}$ & $\%$ \\
\hline $\begin{array}{l}\text { Lifetime } \\
\text { consumption }\end{array}$ & 134 & 78.4 & 132 & 77.2 & 87 & 50.9 & 16 & 9.4 & 7 & 4.1 & 7 & 4.1 & 8 & 4.7 \\
\hline $\begin{array}{l}\text { Last } 30 \text { days } \\
\text { consumption }\end{array}$ & 82 & 48 & 86 & 50.3 & 11 & 6.4 & 0 & 0 & 1 & 0.6 & 0 & 0 & 2 & 1.2 \\
\hline Family & 32 & 18.7 & 28 & 16.4 & 7 & 4.1 & 8 & 4.7 & 4 & 2.3 & 0 & 0 & 0 & 0 \\
\hline
\end{tabular}

\section{Discussion}

We adapted a scale obtaining acceptable psychometric properties that allowed a detailed analysis of the knowledge, beliefs and attitudes about addictions among resident physicians. These were conceptualised in relation to four dimensions, namely importance of knowledge and training in the field of addictions, attitude of professionals towards these patients, views about medical treatment and harm reduction resources in daily clinical practice, and assessment of addiction training received. The first dimension, "Agreement with medical treatment of addictions and harm reduction" dimension explained a $22.91 \%$ of the total variance having also a very good level of reliability. This reflects the unified idea of a global treatment that physicians in training already have.

A statistically significant correlation was found between age and the rating of the training received, understood as the set of good training and knowledge in the field of addictions and experience in the management of these patients. This seems to coincide with other studies remarking the importance of training (Barron et al., 2012a; Karam-Hage et al., 2001). In contrast, year of training did not correlate with any of the other dimensions. This could be explained by the fact that we didn't evaluate professional characteristics in a 
Cite as: Barral, C., Eiroa-Orosa, F. J., Navarro-Marfisis, M. C., Roncero, C., \& Casas, M. (2015). Assessing knowledge and attitudes towards addictions in medical residents of a general hospital. Drugs:

Education, Prevention and Policy, 22(6), 457-462. http://doi.org/10.3109/09687637.2014.987218

detailed way, given the need to preserve the confidentiality and anonymity of study participants. On the other hand, it was found that professionals which were trained in medical specialities (vs. those trained in surgical specialities) had a better attitude to treatment of patients with addiction problems.

The perception of having received a good training and knowledge was found more frequently in residents who were in contact with patients with drug problems. These medical residents also gave more importance to the need of improving knowledge about the diagnosis, treatment and management of addictions. This may be explained by the perceived need to increase knowledge in this field as it can be understood as a way of improving self-perceived safety and management efficacy, having therefore the expectation of better outcomes, and therefore and better attitude when working with this population.

A three percent of our sample reported having problems with at least a substance. We can consider this rate low compared with prevalences among medical professionals described elsewhere (Rose et al., 2014), and the general population (National Plan on Drugs, 2009)Nevertheless, we should consider that our sampling method may had an influence over the results, as even when assuring confidentiality, residents may be suspicious of giving this information. Nevertheless, this gives us information about how own consumption can affect the capacity to manage patients with SUDs. We therefore believe that increasing awareness among physicians in training must be a priority of training programs (Rose et al., 2014).

In relation to personal circumstances, it was found that professionals, who had a history of relatives with an addiction problem, had a more proactive attitude towards these patients. It seems that personal experiences can foster empathy and help to overcome 
Cite as: Barral, C., Eiroa-Orosa, F. J., Navarro-Marfisis, M. C., Roncero, C., \& Casas, M. (2015). Assessing knowledge and attitudes towards addictions in medical residents of a general hospital. Drugs:

Education, Prevention and Policy, 22(6), 457-462. http://doi.org/10.3109/09687637.2014.987218

negative stereotypes. No relationship was found between current or past experiences of illegal substance use, with the attitude of these professionals when treating patients with drug use problems. This result contrasts with what has been proposed in previous studies reflecting how personal experiences with relatives having addiction problems could itself affect physician's ability and willingness to work with patients suffering SUDs (Miller \& Sheppard, 1999). Regarding this, we propose the importance of emotional support in the training of medical residents.

Differences were found between foreign and national professionals. This could be due to the traditional unfavourable beliefs against addiction treatment. We also found female residents to be more prone to report less sense of security when treating patients with drug use problems. To our knowledge, there are no studies with a special gender focus on the management of patients with addictions. We may hypothesize that cultural and social features, may play a role in these gender and national differences.

Compared with the previous literature, an advantage of this study is that it is one of the few in which knowledge is related with attitudes and experiences of health professionals when treating patients with a drug use problem. An additional strong characteristic of this study is that it has a very heterogeneous sample of resident physicians in one of the largest hospitals in Spain, being possible to generalise this data to other university hospitals.

Limitations of the study should also be addressed. As outlined above, confidentiality issues prevented us from asking specific professional issues or other factors that may influence the level of training and experience in managing patients with drug addiction. The implementation format also prevented us to assess for doubts or clarify any 
Cite as: Barral, C., Eiroa-Orosa, F. J., Navarro-Marfisis, M. C., Roncero, C., \& Casas, M. (2015). Assessing knowledge and attitudes towards addictions in medical residents of a general hospital. Drugs:

Education, Prevention and Policy, 22(6), 457-462. http://doi.org/10.3109/09687637.2014.987218

concepts. Other aspect for consideration is the possibility that, even given the anonymity of the online survey, there was an underreporting of own substance use. The study sample (30\% of the whole resident staff) although considered sufficient for the study, may be not representative or at least, was not controlled for self-selection biases. Further studies are needed to assess more accurately how training factors affect attitudes, beliefs and knowledge about addictions among resident physicians. Furthermore, self-reported questionnaires are susceptible of having social desirability biases, resulting in an over reporting of positive attitudes towards patients with SUDs. Nevertheless, the use of an online methodology allowed the participation of many physicians as we ensured anonymity and confidentiality. Finally, regarding the psychometric characteristics of the questionnaire, although the first three subscales had a very good level of reliability, the fourth had a low internal consistency.

Given the overall results of this study, we consider that, stressing the importance of the knowledge and training in the field of addictions in medical residents may be a basic tool to provide better care to these patients, as proper training has a proved impact on daily attitudes and institutional understanding of alternative ways of reaching these patients (Notley et al., 2014). Such initiatives have been undertaken and successfully implemented in countries such as the UK (International Centre for Drud Policy, 2007), Germany (Strobel et al., 2012), the USA (Barron et al., 2012), and Italy (Grassi et al., 2012). Furthermore, the importance of training for an improved care, has been demonstrated internationally (Anderson et al., 2003).

In this study we have considered not only aspects such as training, knowledge or attitudes towards the treatment of SUDs, but we have also addressed residents' prejudices 
Cite as: Barral, C., Eiroa-Orosa, F. J., Navarro-Marfisis, M. C., Roncero, C., \& Casas, M. (2015). Assessing knowledge and attitudes towards addictions in medical residents of a general hospital. Drugs:

Education, Prevention and Policy, 22(6), 457-462. http://doi.org/10.3109/09687637.2014.987218

from different perspectives, such as professional experience and own consumption. These results may allow us to further elaborate addiction training curriculums for physicians and other health professionals in training. We believe that specific training programs focused on the aforementioned aspects, would be needed if the aim is to reduce prejudice and improve physicians' patient management skills. An adequate medical curriculum should include updated clinical information about the management of patients with SUDs, and be better adapted to professionals' actual needs, improving their attitudes towards these patients. As we have seen, attitudes can be a powerful predictor of quality of care. In addition, despite the limitations of the study, we have confirmed substance use in this population of residents, suggesting the need for targeted awareness programs.

\section{Acknowledgements}

This work was supported by the Public Health Agency of Barcelona and with a grant of the Departament de Salut, Government of Catalonia, Spain. We would like to thank the participants of the survey, as well as the Teaching Commission of the Hospital Universitari Vall d'Hebron for their advice and support.

\section{Declaration of interest}

The authors report no conflicts of interest within this study.

\section{References}

Anderson, P., Kaner, E., Wutzke, S., Wensing, M., Grol, R., Heather, N., \& Saunders, J. (2003). Attitudes and management of alcohol problems in general practice: descriptive analysis based on findings of a World Health Organization international collaborative survey. Alcohol and alcoholism, 38(6), 597-601. 
Cite as: Barral, C., Eiroa-Orosa, F. J., Navarro-Marfisis, M. C., Roncero, C., \& Casas, M. (2015). Assessing knowledge and attitudes towards addictions in medical residents of a general hospital. Drugs:

Education, Prevention and Policy, 22(6), 457-462. http://doi.org/10.3109/09687637.2014.987218

Ballon, B. C., \& Skinner, W. (2008). "Attitude is a little thing that makes a big difference": reflection techniques for addiction psychiatry training. Academic psychiatry, 32(3), 218-24. AADPRT.

Barone, E., Huggett, K., \& Lofgreen, A. (2011). Investigation of Students’ Attitudes about Patients with Substance Use Disorders before and after Completing an Online Curricular Module. Annals of Behavioral Science and Medical Education, 17(1), 1013.

Barron, R., Frank, E., \& Gitlow, S. (2012a). Evaluation of an experiential curriculum for addiction education among medical students. Journal of addiction medicine, 6(2), $131-6$.

Barron, R., Frank, E., \& Gitlow, S. (2012b). Evaluation of an experiential curriculum for addiction education among medical students. Journal of addiction medicine, 6(2), $131-6$.

Beletsky, L., Ruthazer, R., Macalino, G. E., Rich, J. D., Tan, L., \& Burris, S. (2007). Physicians' knowledge of and willingness to prescribe naloxone to reverse accidental opiate overdose: challenges and opportunities. Journal of Urban Health, 84(1), 12636.

Van Boekel, L. C., Brouwers, E. P. M., van Weeghel, J., \& Garretsen, H. F. L. (2013). Stigma among health professionals towards patients with substance use disorders and its consequences for healthcare delivery: systematic review. Drug and alcohol dependence, 131(1-2), 23-35. Elsevier Ireland Ltd. 
Cite as: Barral, C., Eiroa-Orosa, F. J., Navarro-Marfisis, M. C., Roncero, C., \& Casas, M. (2015). Assessing knowledge and attitudes towards addictions in medical residents of a general hospital. Drugs:

Education, Prevention and Policy, 22(6), 457-462. http://doi.org/10.3109/09687637.2014.987218

Carroll, J., Goodair, C., Chaytor, A., Notley, C., Ghodse, H., \& Kopelman, P. (2014). Substance misuse teaching in undergraduate medical education. BMC medical education, 14, 34 .

Chappel, J. N. (1993). Training of residents and medical students in the diagnosis and treatment of dual diagnosis patients. Journal of psychoactive drugs, 25(4), 293-300.

Choi, D., Tolova, V., Socha, E., \& Samenow, C. P. (2013). Substance use and attitudes on professional conduct among medical students: a single-institution study. Academic psychiatry: the journal of the American Association of Directors of Psychiatric Residency Training and the Association for Academic Psychiatry, 37(3), 191-5.

Cottler, L. B., Ajinkya, S., Merlo, L. J., Nixon, S. J., Ben Abdallah, A., \& Gold, M. S. (2013). Lifetime psychiatric and substance use disorders among impaired physicians in a physicians health program: comparison to a general treatment population: psychopathology of impaired physicians. Journal of addiction medicine, 7(2), 108-12.

Deren, S., Kang, S.-Y., Mino, M., \& Seewald, R. M. (2011). Attitudes of methadone program staff toward provision of harm-reduction and other services. Journal of addiction medicine, 5(4), 289-92.

Ding, L., Landon, B. E., Wilson, I. B., Wong, M. D., Shapiro, M. F., \& Cleary, P. D. (2005). Predictors and consequences of negative physician attitudes toward HIVinfected injection drug users. Archives of internal medicine, 165(6), 618-23.

European Monitoring Centre for Drugs and Drug Addiction. (2010). Annual report on the state of the drugs problem in Europe. 
Cite as: Barral, C., Eiroa-Orosa, F. J., Navarro-Marfisis, M. C., Roncero, C., \& Casas, M. (2015). Assessing knowledge and attitudes towards addictions in medical residents of a general hospital. Drugs:

Education, Prevention and Policy, 22(6), 457-462. http://doi.org/10.3109/09687637.2014.987218

Flaherty, J. A., \& Richman, J. A. (1993). Substance use and addiction among medical students, residents, and physicians. The Psychiatric clinics of North America, 16(1), 189-97.

Friedmann, P. D., McCullough, D., \& Saitz, R. (2001). Screening and intervention for illicit drug abuse: a national survey of primary care physicians and psychiatrists. Archives of Internal Medicine, 161(2), 248-51.

Gerlach, R., \& Caplehorn, J. R. M. (1999). Attitudes and beliefs of doctors prescribing methadone to addicts in the Westfalen-Lippe region of Germany. Drug and Alcohol Review, 18(2), 163-170. Blackwell Publishing Ltd.

Gilchrist, G., Moskalewicz, J., Slezakova, S., Okruhlica, L., Torrens, M., Vajd, R., \& Baldacchino, A. (2011). Staff regard towards working with substance users: a European multi-centre study. Addiction (Abingdon, England), 106(6), 1114-25.

Gili Miner, M., Giner, J., Lacalle, J. R., Franco, D., \& Velasco, A. (1990). [Detection of alcohol-related problems in primary care]. Gaceta Sanitaria, 4(19), 135-139.

Goddard, P. (2003). Changing attitudes towards harm reduction among treatment professionals: a report from the American Midwest. International Journal of Drug Policy, 14(3), 257-260.

Grassi, M. C., Chiamulera, C., Baraldo, M., Culasso, F., Ferketich, A. K., Raupach, T., Patrono, C., et al. (2012). Cigarette smoking knowledge and perceptions among students in four Italian medical schools. Nicotine \& tobacco research : official journal of the Society for Research on Nicotine and Tobacco, 14(9), 1065-72. 
Cite as: Barral, C., Eiroa-Orosa, F. J., Navarro-Marfisis, M. C., Roncero, C., \& Casas, M. (2015). Assessing knowledge and attitudes towards addictions in medical residents of a general hospital. Drugs:

Education, Prevention and Policy, 22(6), 457-462. http://doi.org/10.3109/09687637.2014.987218

Howard, V., \& Holmshaw, J. (2010). Inpatient staff perceptions in providing care to individuals with co-occurring mental health problems and illicit substance use. Journal of psychiatric and mental health nursing, 17(10), 862-72.

International Centre for Drud Policy. (2007). Substance Misuse in the Undergraduate Medical Curriculum. London: International Centre for Drug Policy.

Karam-Hage, M., Nerenberg, L., \& Brower, K. J. (2001). Modifying residents' professional attitudes about substance abuse treatment and training. The American Journal on Addictions, 10(1), 40-47.

Kelleher, S., \& Cotter, P. (2009). A descriptive study on emergency department doctors' and nurses' knowledge and attitudes concerning substance use and substance users. International emergency nursing, 17(1), 3-14. Elsevier Ltd.

Lawrence, R. E., Rasinski, K. A., Yoon, J. D., \& Curlin, F. A. (2013). Physicians' Beliefs about the nature of addiction: a survey of primary care physicians and psychiatrists. The American journal on addictions, 22(3), 255-60.

Lindberg, M., Vergara, C., Wild-Wesley, R., \& Gruman, C. (2006). Physicians-in-training attitudes toward caring for and working with patients with alcohol and drug abuse diagnoses. Southern medical journal, 99(1), 28-35.

McBeth, B. D., \& Ankel, F. K. (2006). Don't ask, don't tell: substance use by resident physicians. Academic emergency medicine : official journal of the Society for Academic Emergency Medicine, 13(8), 893-5.

Miller, N. S., \& Sheppard, L. M. (1999). The role of the physician in addiction prevention and treatment. Psychiatric Clinics of North America, 22(2), 489-505. Elsevier. 
Cite as: Barral, C., Eiroa-Orosa, F. J., Navarro-Marfisis, M. C., Roncero, C., \& Casas, M. (2015). Assessing knowledge and attitudes towards addictions in medical residents of a general hospital. Drugs:

Education, Prevention and Policy, 22(6), 457-462. http://doi.org/10.3109/09687637.2014.987218

Miller, N. S., Sheppard, L. M., Colenda, C. C., \& Magen, J. (2001). Why physicians are unprepared to treat patients who have alcohol- and drug-related disorders. Academic Medicine, 76(5), 410-8.

National Plan on Drugs. (2009). 2009 Report. Madrid: Government Delegation for the National Plan on Drugs.

Notley, C., Goodair, C., Chaytor, A., Carroll, J., Ghodse, H., \& Kopelman, P. (2014). Report of the substance misuse in the undergraduate medical curriculum project in England. Drugs: Education, Prevention, and Policy, 21(2), 173-176.

Renner, J. a. (2004). How to train residents to identify and treat dual diagnosis patients. Biological psychiatry, 56(10), 810-6.

Rose, J. S., Campbell, M., \& Skipper, G. (2014). Prognosis for Emergency Physician with Substance Abuse Recovery: 5-year Outcome Study. The western journal of emergency medicine, 15(1), 20-5.

Saitz, R., Friedmann, P. D., Sullivan, L. M., Winter, M. R., Lloyd-Travaglini, C., Moskowitz, M. A., \& Samet, J. H. (2002). Professional satisfaction experienced when caring for substance-abusing patients: faculty and resident physician perspectives. Journal of General Internal Medicine, 17(5), 373-6.

Saitz, R., Mulvey, K. P., Plough, A., \& Samet, J. H. (1997). Physician Unawareness of Serious Substance Abuse. The American Journal of Drug and Alcohol Abuse, 23(3), 343-354. Informa Allied Health.

Strobel, L., Schneider, N. K., Krampe, H., Beißbarth, T., Pukrop, T., Anders, S., West, R., et al. (2012). German medical students lack knowledge of how to treat smoking and problem drinking. Addiction, 107(10), 1878-1882. 
Cite as: Barral, C., Eiroa-Orosa, F. J., Navarro-Marfisis, M. C., Roncero, C., \& Casas, M. (2015). Assessing knowledge and attitudes towards addictions in medical residents of a general hospital. Drugs:

Education, Prevention and Policy, 22(6), 457-462. http://doi.org/10.3109/09687637.2014.987218

Van Boekel, L.C., Brouwers, E.P.M., van Weeghel, J., \& Garretsen, H.F.L. (2013). Stigma among health professionals towards patients with substance use disorders and its consequences for healthcare delivery: Systematic review. Drug and Alcohol Dependence, 131, 23-35. 